OPEN ACCESS

Edited by:

Adam J. Woods,

University of Florida, United States

Reviewed by:

Nabin Koirala

Haskins Laboratories, United States Heidemarie Zach,

Medical University of Vienna, Austria

${ }^{*}$ Correspondence: Wei-Peng Teo weipeng.teo@nie.edu.sg

Received: 05 March 2020

Accepted: 13 July 2020

Published: 14 August 2020

Citation:

Leuk JSP, Low LLN and Teo W-P (2020) An Overview of

Acoustic-Based Interventions to Improve Motor Symptoms in

Parkinson's Disease.

Front. Aging Neurosci. 12:243. doi: 10.3389/fnagi.2020.00243

\section{An Overview of Acoustic-Based Interventions to Improve Motor Symptoms in Parkinson's Disease}

\author{
Jessie Siew Pin Leuk ${ }^{1}$, Linette Li Neng Low ${ }^{1}$ and Wei-Peng Teo ${ }^{1,2 *}$ \\ ${ }^{1}$ Physical Education and Sports Science (PESS) Academic Group, National Institute of Education, Nanyang Technological \\ University, Singapore, Singapore, ${ }^{2}$ Institute for Physical Activity and Nutrition (IPAN), School of Exercise and Nutrition \\ Sciences, Deakin University, Geelong, VIC, Australia
}

Parkinson's disease (PD) is characterized by motor and cognitive deficits that negatively impact on activities of daily living. While dopaminergic medications are used to attenuate motor symptoms, adjuvant therapies such as acoustic-based non-pharmacological interventions are used as a complement to standard drug treatments. At present, preliminary studies of acoustic-based interventions such as rhythmic-auditory stimulation (RAS) and vibroacoustic therapy (VAT) suggest two competing hypotheses: (1) RAS may recruit alternative motor networks that may bypass faulty spatiotemporal motor networks of movement in PD; or (2) the use of RAS enhances BG function through entrainment of beta oscillatory activities. In this mini review article, we discuss the mechanisms underlying the role of acoustic-based interventions and how it may serve to improve motor deficits such as gait impairments and tremors. We further provide suggestions for future work that may use a combination of RAS, VAT, and physical therapy to improve motor function in PD.

\footnotetext{
Keywords: music therapy (MT), Parkinson's disease, motor symptom (MDS-UPDRS-III), rhythm entrainment, acoustic therapy
}

\section{INTRODUCTION}

Parkinson's Disease (PD) is the second most ubiquitous neurodegenerative disorder that affects approximately $1 \%$ of individuals aged over 60 (Reeve et al., 2014). The prevalence of PD increases with age, and with an aging population, the number of individuals with PD is expected to double in the next decade (Rizek et al., 2016). Individuals with PD exhibit both motor (tremor; rigidity; bradykinesia) and non-motor related symptoms (cognitive; neurobehavioural abnormalities; and sleep disorders) that stems from dopamine depletion in the substantia nigra within the basal ganglia (BG; Chaudhuri et al., 2006; Sveinbjornsdottir, 2016). While dopaminergic medications can effectively manage symptoms, drug-resistance and levodopa-induced dyskinesias are common side-effects following long-term use (Vorovenci et al., 2016). Adjuvant physical therapies such as acoustic-based interventions may therefore be efficacious in promoting wellness and maintenance of physical and cognitive health in PD.

Music is an effective mood relaxer (Magee and Davidson, 2002), beneficial in relieving anxiety, pain, and stress (Nilsson, 2008) at a low cost. Recent advancements in brain imaging have allowed us to revise how our brains respond to music (Hunt, 2015). An established view is that music induces adaptable changes in the auditory-motor network, that may facilitate 
functional recovery of movements, thus may be harnessed in the treatment of motor-related disorders (Sihvonen et al., 2017). Neuroimaging studies have further reported the recruitment of sensorimotor areas during music listening in the absence of movement (Gordon et al., 2018), and enhanced motor connections in stroke patients during the musical intervention (Altenmüller et al., 2009). Furthermore, studies suggested a close connection between auditory, BG (Nombela et al., 2013), and cerebellar networks (Thaut et al., 2009). Since music can modulate neural activities that are implicated in $\mathrm{PD}$, it is plausible that acoustic-based intervention may represent a low-cost yet effective treatment for people with PD.

Indeed, acoustic-based interventions have previously been shown to improve gait parameters (see Table $\mathbf{1}$ for studies using acoustic-based intervention in PD). A common method of acoustic-based intervention used in neurorehabilitation in $\mathrm{PD}$ is rhythmic auditory stimulation (RAS) in which external auditory cues (i.e., beat of a metronome) are applied to synchronize or provide timing to the movement (Ghai et al., 2018). A typical RAS procedure starts with presenting beats of a metronome that match an individual's baseline cadence. The metronome beats are then gradually adjusted to an optimal pace, and individuals are tasked to synchronize their steps with the beats. This process requires the entrainment of movements to external auditory cues; the latter involves the coordination of timing and movement sequencing (Thaut, 2005). This mini-review will attempt to discuss the common types of acoustic-based interventions used to improve motor symptoms associated with PD. Additionally, we will provide suggestions for future investigations and plausible mechanisms underlying the role of acoustics in normalizing the aberrant neurophysiology of PD.

\section{MECHANISMS UNDERPINNING RAS}

In RAS, the application of external auditory cues serves as a time reference to regulate walking pace to external rhythm, allowing temporal expectations (anticipation of the next steps) to occur (Rohenkohl et al., 2012; Nombela et al., 2013). Motor symptoms in PD are likely due to faulty temporal and spatial mechanisms, necessary for coordinating and initiating structured movements (Jones et al., 2008). Therefore, auditory cues can act as an "internal clock" to stabilize aberrant internal rhythm in PD individuals via neural entrainment. An fMRI study by Grahn (2009) found that when the internal generation of beats was needed, the BG, specifically putamen activity was lowered with the presence of strong external beats. This suggests that the putamen may play a crucial role in mental beat prediction and generating accurate motor execution pace.

Besides its role in time perception to regulate movement, the BG mediates the interaction between auditory and motor systems during rhythm perception. This results in the engagement of motor areas (i.e., supplementary and premotor areas) when people attend to rhythms (Zatorre et al., 2007; Grahn, 2009; Grahn and Rowe, 2013; Ashoori et al., 2015; Raglio, 2015), which underpins the concept of RAS. Herein, we ask if RAS can potentially confer improvement when key brain areas required for rhythm and/or motor timing perception are impaired? The answer may be two-fold, with distinct hypotheses: Compensation and Restoration (Figure 1).

\section{THE COMPENSATION HYPOTHESIS}

The compensation theory suggests that while the BG is impaired in $\mathrm{PD}$, other cortical structures may execute the functions of rhythm perception typically performed by the BG. Acoustic rhythms may reinforce alternate networks, such as the cerebellothalamocortical circuitry, to modulate neural entrainment and enhance motor functioning (Schwartze et al., 2011; Nombela et al., 2013). When movements were externally cued, studies have shown increased activation within the lateral premotor cortex (PMC), and cerebellar connections to motor cortices (Sen et al., 2010; Todd and Lee, 2015), which effectively bypasses the impaired striato-thalamocortical circuitry. Moreover, Fernandez del Olmo et al. (2006) reported elevated glucose uptake in the cerebellum of individuals with PD post-RAS training using positron emission tomography (PET) concomitant to reductions in the variability of gait and finger-tapping tasks. The enhanced cerebellar activity after a month of RAS may imply that cerebellar pathways have been recruited to compensate for the impaired BG-cortical circuitry.

\section{THE RESTORATION HYPOTHESIS}

In contrast, some reviews suggest that acoustic rhythms may facilitate impaired BG network in individuals with PD (Nombela et al., 2013; Raglio, 2015) rather than bypassing it as suggested by the Compensation Hypothesis. Beta activity is excessively synchronized in individuals with PD leading to motor dysfunctions (Little and Brown, 2012; Sharott et al., 2014). The mechanistic rationale of RAS in PD is therefore to normalize beta-band coupling of the motor network, which may provide similar effects to current treatments (i.e., deep brain stimulation and dopaminergic therapy) without surgery or medication (Ghai et al., 2018).

The Restoration Hypothesis is supported by a study conducted by Woerd et al. (2014), which suggested that RAS was beneficial only if there was an increase in modulation depth of beta oscillatory activity, defined as the difference between eventrelated synchronization and desynchronization (ERS/ERD). Their study showed that relative to controls, individuals with PD had lesser ERD before the cue, with greater ERD after cue, probably due to compensation. Therefore, increases in beta ERS reflected the involvement of the BG as a beat predictor in rhythm processing, whereas increases in beta ERD is likely to reflect compensatory mechanisms. The findings from Woerd et al. (2014) showed that gains in modulation depth of beta activity are comparable amongst patients and controls. Moreover, the gains are entirely due to increases in synchronization, conferring increased predictive movement-related beta power suppression. This indicates that the BG is involved in rhythm and motor timing perception in individuals with $\mathrm{PD}$ and that RAS facilitates this process.

Overall, both hypotheses have valid supporting evidence and at present, we have yet reached consensus about the neuroplastic 
TABLE 1 | Effects of auditory therapy (stimulation and vibration) on motor symptoms of PD.

\begin{tabular}{|c|c|c|c|c|c|}
\hline References & Subjects & $\begin{array}{l}\text { Motor symptoms } \\
\text { severity }\end{array}$ & Intervention and assessments & Outcomes & Conclusion \\
\hline Buard et al. (2019) & $\begin{array}{l}\text { Three PD patients ("on" } \\
\text { state) }\end{array}$ & $\begin{array}{l}\text { Y\&H scale: 2-3 } \\
\text { UPDRS III score: 23-52 }\end{array}$ & $\begin{array}{l}\text { Stimuli: } \\
\text { Auditory cueing via metronome or beats } \\
\text { produced by musical instrument (frequency: } \\
\text { NS) } \\
\text { Task: } \\
\text { Bimanual exercises using keyboard, } \\
\text { castanets and miscellaneous objects to } \\
\text { strengthen fine motor muscles } \\
\text { (3 times/week for } 5 \text { weeks) } \\
\text { Assessments: } \\
\text { UPDRS III, Grooved Pegboard Test, } \\
\text { Finger-Thumbs Opposition Task were } \\
\text { assessed pre and post-intervention period }\end{array}$ & $\begin{array}{l}\text { Motor: } \\
\text { Improved performance in overall motor } \\
\text { assessments } \\
\text { two out of three subjects improved in } \\
\text { Grooved Pegboard and Finger-Thumbs } \\
\text { Opposition Tasks } \\
\text { Neurophysiology: } \\
\text { Spectral analysis in primary motor and } \\
\text { auditory cortices showed a simultaneous } \\
\text { increase in evoked power in the beta-range, } \\
\text { increased motor-auditory functional } \\
\text { connectivity }\end{array}$ & $\begin{array}{l}\text { Improvements in task performance were } \\
\text { not consistent in all subjects but all of them } \\
\text { benefitted in one or more fine motor } \\
\text { function } \\
\text { NMT-based motor rehabilitation enhances } \\
\text { motor-auditory cortical activation in a } \\
\text { synergic manner }\end{array}$ \\
\hline $\begin{array}{l}\text { Calabro et al. } \\
\text { (2019) }\end{array}$ & $\begin{array}{l}\text { Fifty Non-demented } \\
\text { idiopathic PD patients } \\
\text { ("on" state): } 25 \text { in RAS } \\
\text { group and } 25 \text { in No } \\
\text { RAS group }\end{array}$ & Y\&H scale: $2-3$ & $\begin{array}{l}\text { Stimuli: } \\
\text { Auditory stimuli via music and the beats } \\
\text { were emphasized with superimposed } \\
\text { salient high-pitch bell sound (frequency: } \\
\text { increase gradually up to } 120 \text { bpm through } \\
\text { first } 3-5 \text { trials) } \\
\text { Tasks: Walk on the treadmill with/without } \\
\text { salient beats (GaitTrainer3), real-time } \\
\text { feedback provided (5 times/week for } \\
8 \text { weeks) } \\
\text { Assessments: } \\
\text { Functional measures (FGA, UPDRS, BBS, } \\
\text { Tinetti FES, 10MWT TUG, and GQI) were } \\
\text { assessed at pre and post-intervention } \\
\text { period } \\
\text { Brain oscillation changes within the frontal, } \\
\text { centroparietal, and temporal areas that } \\
\text { were related to the gait cycle }\end{array}$ & $\begin{array}{l}\text { Motor: } \\
\text { RAS group showed greater improvements } \\
\text { in overall gait quality, balance, number, } \\
\text { length of strides and UPDRS scores } \\
\text { compared to no RAS group } \\
\text { A significant correlation between changes in } \\
\text { connectivity measurements and gait } \\
\text { Neurophysiology: } \\
\text { RAS group showed significant changes in } \\
\text { gait-related } \alpha \text { and } \beta \text { ERS and ERD within } \\
\text { frontal and centroparietal areas compared } \\
\text { to no RAS group } \\
\text { RAS group showed stronger entrainment of } \\
\beta \text { oscillations between fronto-centroparietal } \\
\text { and fronto-temporal connectivity compared } \\
\text { to no RAS group }\end{array}$ & $\begin{array}{l}\text { RAS improves overall gait quality, balance, } \\
\text { number, and length of strides. } \\
\text { Rhythmic entrainment shown in RAS group } \\
\text { may indicate a restoration of internal timing } \\
\text { mechanism via a compensatory network }\end{array}$ \\
\hline $\begin{array}{l}\text { Cochen De Cock } \\
\text { et al. (2018) }\end{array}$ & $\begin{array}{l}\text { Thirty-nine } \\
\text { non-demented PD } \\
\text { patients ("on" state): } \\
22 \text { in positive response } \\
\text { (PR) group and } 17 \text { in } \\
\text { Non-positive response } \\
\text { (NPR) group } \\
\text { Thirty nine matched } \\
\text { healthy controls }\end{array}$ & $\begin{array}{l}\text { Y\&H scale: } 2 \pm 0.5 \\
\text { UPDRS III score: } \\
24.3 \pm 13.2\end{array}$ & $\begin{array}{l}\text { Stimuli: } \\
\text { Auditory cueing via metronome and musical } \\
\text { excerpts from four military marches } \\
\text { (frequency: } 10 \% \text { faster than patient's } \\
\text { preferred cadence measured at pre-test) } \\
\text { Task: } \\
\text { Respond to the rhythmic stimuli and } \\
\text { movement measured via 3D } \\
\text { accelerometers and gyroscope } \\
\text { PR groups were more musically trained, } \\
\text { showed strong gait synchronization to the } \\
\text { beat and better music perception compared } \\
\text { to the non-positive response group (NPR). }\end{array}$ & $\begin{array}{l}\text { Motor: } \\
\text { PR group improved speed and stride length } \\
\text { in contrast to the NPR group who showed } \\
\text { worsening performance with rhythmic cues }\end{array}$ & $\begin{array}{l}\text { While PD has timing and rhythmic deficits, } \\
\text { patients in the PR group can still } \\
\text { synchronize to beats } \\
\text { Subject's rhythmic abilities and musical } \\
\text { training may affect their response to } \\
\text { auditory cueing }\end{array}$ \\
\hline
\end{tabular}


TABLE 1 | Continued

\begin{tabular}{|c|c|c|c|c|c|}
\hline References & Subjects & $\begin{array}{l}\text { Motor symptoms } \\
\text { severity }\end{array}$ & Intervention and assessments & Outcomes & Conclusion \\
\hline & & & $\begin{array}{l}\text { Assessments: } \\
\text { Gait parameters (cadence, velocity, stride } \\
\text { length, variability, coordination) and } \\
\text { rhythmic/musical abilities (BAASTA, beat } \\
\text { alignment test, finger tapping task, and } \\
\text { Gold-MSI) were assessed pre and post } \\
\text { auditory cueing }\end{array}$ & & \\
\hline $\begin{array}{l}\text { Harrison et al. } \\
\text { (2018) }\end{array}$ & $\begin{array}{l}\text { Thirty non-demented } \\
\text { PD patients ("on" state) } \\
30 \text { young controls aged } \\
18-35 \\
\text { Thirty older controls } \\
\text { aged } \geq 50\end{array}$ & $\begin{array}{l}\text { UPDRS III score: } \\
24.9 \pm 10.27\end{array}$ & $\begin{array}{l}\text { Stimuli: } \\
\text { Internal cueing via singing aloud and } \\
\text { walking to the beat of their singing. External } \\
\text { cueing via music playing and walking to the } \\
\text { beat of the song (frequency: patient's } \\
\text { preferred cadence measured at baseline) } \\
\text { Task: Forward and backward walking trials } \\
\text { (5 m GAITRite Walkway) in non-cued and } \\
\text { cued conditions } \\
\text { Assessments: } \\
\text { Gait parameters (velocity, cadence, stride } \\
\text { length, variability) }\end{array}$ & $\begin{array}{l}\text { Motor: } \\
\text { PD exhibits greater improvements } \\
\text { compared to controls. } \\
\text { During internal cueing (singing), improved } \\
\text { gait velocity, cadence and stride length in } \\
\text { backward walking, and reduced gait } \\
\text { variability in both forward and backward } \\
\text { walking } \\
\text { During external cueing (music playing), } \\
\text { minimal improvement in gait characteristic } \\
\text { and higher gait variability compared to } \\
\text { internal cueing }\end{array}$ & $\begin{array}{l}\text { Auditory cueing improves gait in PD, } \\
\text { particularly in backward moving (more } \\
\text { challenging gait situation) } \\
\text { Internal cueing via singing may be more } \\
\text { beneficial to gait compared to external } \\
\text { cueing }\end{array}$ \\
\hline Murgia et al. (2018) & $\begin{array}{l}\text { Thirty-two } \\
\text { non-demented PD } \\
\text { patients ("on" state): } \\
16 \text { in ecological RAS } \\
\text { group and } 16 \text { in the } \\
\text { artificial RAS group }\end{array}$ & $\begin{array}{l}\text { Ecological RAS group- } \\
\text { Y\&H scale: } 1.5-2.5 \\
\text { UPDRS III score: } \\
18.0 \pm 9.1 \\
\text { Artificial RAS group- } \\
\text { Y\&H scale: } 1.5-3 \\
\text { UPDRS III score: } \\
20.2 \pm 9.6\end{array}$ & $\begin{array}{l}\text { Stimuli: } \\
\text { Ecological RAS via footsteps recording that } \\
\text { was chosen from a database.Artificial RAS } \\
\text { via metronome sounds (frequency: } \\
\text { personalized by comparing cadence in } \\
\text { matched healthy individuals and the } \\
\text { patient's baseline cadence) } \\
\text { Task: Walk along } 10 \text { m walkway while } \\
\text { listening to either ecological or artificial RAS } \\
\text { soundtrack } \\
\text { (45 min/session, } 2 \text { times/week for } 5 \text { weeks) } \\
\text { Assessments: } \\
\text { Gait parameters (speed, length width, } \\
\text { cadence, stance, swing, double support } \\
\text { phase duration) and clinical measurements } \\
\text { (i.e., FES, FOGQ, Y\&H scale) were } \\
\text { assessed with a motion capture system at } \\
\text { pre, post and } 3 \text { months after the } \\
\text { intervention period }\end{array}$ & $\begin{array}{l}\text { Motor: } \\
\text { RAS type showed no comparable } \\
\text { differences. } \\
\text { Improved overall gait and clinical measures } \\
\text { during the post- and follow-up intervention. } \\
\text { Exploratory analyses for separate groups } \\
\text { showed Spatio-temporal gait improvements } \\
\text { in ecological RAS group only }\end{array}$ & $\begin{array}{l}\text { Ecological and artificial RAS are equally } \\
\text { effective in improving gait and clinical } \\
\text { assessment scores }\end{array}$ \\
\hline Benoit et al. (2014) & $\begin{array}{l}\text { Fifteen non-demented } \\
\text { idiopathic PD patients } \\
\text { ("on" state) } \\
20 \text { matched healthy } \\
\text { controls }\end{array}$ & $\begin{array}{l}\text { Y\&H scale: } 2 \pm 0.7 \\
\text { UPDRS score: } \\
37.7 \pm 18.8\end{array}$ & $\begin{array}{l}\text { Stimuli: } \\
\text { Auditory cueing via songs played without } \\
\text { lyrics and the beats were emphasized with } \\
\text { superimposed salient high-pitch bell sound } \\
\text { (frequency: } \pm 10 \% \text { of patient's preferred } \\
\text { cadence measured at first session) }\end{array}$ & $\begin{array}{l}\text { Motor: } \\
\text { Increased stride length during the post- and } \\
\text { follow-up intervention } \\
\text { Improved performance and ability to detect } \\
\text { changes in synchronization task, hand } \\
\text { tapping task, duration discrimination and } \\
\text { detection of misaligned beats }\end{array}$ & $\begin{array}{l}\text { Auditory cueing improves perceptual and } \\
\text { motor timing beyond gait }\end{array}$ \\
\hline
\end{tabular}


TABLE 1 | Continued

\begin{tabular}{|c|c|c|c|c|c|}
\hline References & Subjects & $\begin{array}{l}\text { Motor symptoms } \\
\text { severity }\end{array}$ & Intervention and assessments & Outcomes & Conclusion \\
\hline & & & $\begin{array}{l}\text { Task: } \\
\text { Walk to the beats and continue walking } \\
\text { when the beat stopped, including a } \\
\text { stop-and-go phase. } \\
\text { Subjects were not explicitly instructed to } \\
\text { synchronize footsteps to the beat of the } \\
\text { music ( } 3 \text { times/week for } 1 \text { month) } \\
\text { Assessments: } \\
\text { Perceptual and movement tasks (BAASTA) } \\
\text { were assessed pre, post and } 1 \text { month after } \\
\text { the intervention period }\end{array}$ & & \\
\hline Kadivar et al. (2011) & $\begin{array}{l}\text { Sixteen non-demented } \\
\text { idiopathic PD patients } \\
\text { ("on" state): } 8 \text { in RAS } \\
\text { groups and } 8 \text { in No } \\
\text { RAS group }\end{array}$ & $\begin{array}{l}\text { Y\&H scale: } 2-4 \\
\text { UPDRS III score: } \\
\text { RAS group- } 27.1 \pm 4.1 \\
\text { No RAS group- } \\
27.0 \pm 3.8\end{array}$ & $\begin{array}{l}\text { Stimuli: } \\
\text { Auditory cueing via "cluck," "ding" and "soft } \\
\text { cork" sounds (frequency: patient's preferred } \\
\text { cadence determined by averaging first five } \\
\text { trials, } \pm 10 \%, \pm 20 \% \text { ) } \\
\text { Task: } \\
\text { Multidirectional step training with RAS at } \\
\text { different frequencies. No RAS group } \\
\text { performed self-selected, internally paced } \\
\text { stepping ( } 3 \text { times/week for } 6 \text { weeks) } \\
\text { Assessments: } \\
\text { Functional measures (DGI, TUG, UPDRS, } \\
\text { FOGQ, Tinetti gait and balance) were } \\
\text { assessed pre, post and at different } \\
\text { follow-up time points (1, } 4,8 \text { weeks after } \\
\text { post-intervention) }\end{array}$ & $\begin{array}{l}\text { Motor: } \\
\text { RAS group showed greater improvements } \\
\text { in DGl scores compared to no RAS group } \\
\text { Improvements in other functional measures } \\
\text { were comparable in both groups } \\
\text { RAS group maintained improvements in gait } \\
\text { and balance longer than No RAS group }\end{array}$ & $\begin{array}{l}\text { Step training with RAS improves functional } \\
\text { gait and balance that could maintain over } \\
8 \text { weeks }\end{array}$ \\
\hline $\begin{array}{l}\text { Rochester et al. } \\
\text { (2009) }\end{array}$ & $\begin{array}{l}\text { Nine non-demented } \\
\text { idiopathic PD patients } \\
\text { with a modest degree } \\
\text { of cognitive impairment }\end{array}$ & $\begin{array}{l}\text { Y\&H scale: } 3 \pm 2.5-3 \\
\text { UPDRS score: } \\
44 \pm 35.5-47 \\
\text { Modified dyskinesia } \\
\text { score: > } 2 \\
\text { FOGQ scores: } \\
11 \pm 9-15.5 \\
\text { Tinetti gait and balance } \\
\text { scale: } 19.78 \pm 4.41\end{array}$ & $\begin{array}{l}\text { Stimuli: } \\
\text { Metronome (frequency: patient's preferred } \\
\text { cadence determined by averaging first three } \\
\text { trials) } \\
\text { Task: } \\
\text { Walk only task on GAITRite and dual-task } \\
\text { (walk while carrying a tray with two } \\
\text { water-filled cups) with or without a cue. Cue } \\
\text { either focusing on the temporal parameter } \\
\text { (step in time to the beat) or spatiotemporal } \\
\text { parameter (take a big step in time to the } \\
\text { beat) } \\
\text { Assessments: } \\
\text { Gait parameters (walking speed, stride } \\
\text { amplitude, cadence, step time, double limb } \\
\text { support time, variability), UPDRS III }\end{array}$ & $\begin{array}{l}\text { Motor: } \\
\text { Cue focusing on spatiotemporal parameter } \\
\text { showed great improvements in walking } \\
\text { speed, stride amplitude and cadence in } \\
\text { both single and dual-task } \\
\text { Cue focusing on temporal parameter } \\
\text { showed improvements in cadence }\end{array}$ & $\begin{array}{l}\text { Auditory cueing (especially cueing focusing } \\
\text { on step length while being prompted to } \\
\text { maintain cadence) improved motor } \\
\text { symptoms in PD patients with mild } \\
\text { cognitive impairment }\end{array}$ \\
\hline
\end{tabular}

\section{G}

Rochester et al. idiopathic PD patients with a modest degree UPDRS score: 35.5-47 score: >2

Tinetti gait and balance scale: $19.78 \pm 4.41$ 
TABLE 1 | Continued

\begin{tabular}{|c|c|c|c|c|c|}
\hline References & Subjects & $\begin{array}{l}\text { Motor symptoms } \\
\text { severity }\end{array}$ & Intervention and assessments & Outcomes & Conclusion \\
\hline $\begin{array}{l}\text { Fernandez del } \\
\text { Olmo et al. (2006) }\end{array}$ & $\begin{array}{l}\text { Nine non-demented } \\
\text { idiopathic PD patients } \\
\text { ("on" state): } \\
4 \text { akinetic-rigid } \\
\text { dominant and five } \\
\text { tremor dominant } \\
\text { five matched healthy } \\
\text { controls }\end{array}$ & $\begin{array}{l}\text { Y\&H scale: } 1-2.5 \\
\text { UPDRS score: } 12-45\end{array}$ & $\begin{array}{l}\text { Stimuli: Auditory cues via metronome } \\
\text { (frequency: } 60,90,120,150 \text { bpm) } \\
\text { Task: Walk along } 30 \text { m walkway while } \\
\text { performing specific increasingly } \\
\text { complicated tasks in two conditions: } \\
\text { reproduce walking speed after listening to } \\
\text { metronome playing at different frequencies, } \\
\text { synchronize walking with the presence of } \\
\text { metronome playing at different frequencies } \\
(1 \mathrm{~h} / \text { day, } 5 \text { days/week for } 4 \text { weeks) } \\
\text { Assessments: } \\
\text { Gait parameter (velocity, length, cadence, } \\
\text { variability) and finger tapping performance } \\
\text { were assessed pre and post-intervention } \\
\text { period }\end{array}$ & $\begin{array}{l}\text { Motor: } \\
\text { Interval time between taps and between } \\
\text { steps was more regular } \\
\text { after the intervention period } \\
\text { Other gait parameters did not reach } \\
\text { significant improvements after the } \\
\text { intervention } \\
\text { Neurophysiology: } \\
\text { PET analysis showed increased glucose } \\
\text { uptake in the right anterior lobule of the } \\
\text { cerebellum, dentate nucleus near the } \\
\text { midline and right temporoparietal } \\
\text { conjunction after training }\end{array}$ & $\begin{array}{l}\text { Auditory cueing improves temporal } \\
\text { variability of gait and finger tapping, along } \\
\text { with increase metabolism in sensorimotor } \\
\text { areas which indicate access to cerebellar } \\
\text { projections to compensate for the } \\
\text { damage BG }\end{array}$ \\
\hline King et al. (2009) & $\begin{array}{l}\text { Forty non-demented } \\
\text { idiopathic PD patients } \\
\text { ("on" state): } \\
20 \text { slow/rigid dominant } \\
\text { and } 20 \text { tremors } \\
\text { dominant }\end{array}$ & Not specified & $\begin{array}{l}\text { Stimuli: } \\
\text { Whole-body sound wave vibration via } \\
\text { psychoacoustic chair (five series lasting } \\
1 \text { min each with } 1 \text {-min rest in between, } \\
\text { frequency: } 27-113 \mathrm{~Hz} \text { ) } \\
\text { Task: Close eyes and relax during vibration. } \\
\text { Walking task only (GAITRite) to assess gait. } \\
\text { Assessments: } \\
\text { UPDRS, gait parameters (velocity, step } \\
\text { length), grooved pegboard performance } \\
\text { were assessed at pre, post vibration and } \\
\text { after a control rest period }\end{array}$ & $\begin{array}{l}\text { Motor: } \\
\text { The dominant Symptom category showed } \\
\text { no comparable differences. } \\
\text { Decreased rigidity and tremor, increased } \\
\text { step length, improved speed on pegboard } \\
\text { task (corresponding with reduced } \\
\text { bradykinesia) after vibration } \\
\text { Other UPDRS measures for posture, leg } \\
\text { agility and sitting to standing scores did not } \\
\text { reach significant improvements }\end{array}$ & $\begin{array}{l}\text { The patient's dominant symptom does not } \\
\text { affect the treatment outcome. } \\
\text { Vibration therapy improves the primary } \\
\text { motor symptoms of PD (rigidity, tremors, } \\
\text { and bradykinesia) }\end{array}$ \\
\hline Haas et al. (2006) & $\begin{array}{l}\text { Sixty-eight non- } \\
\text { demented idiopathic } \\
\text { PD patients ("on" state) }\end{array}$ & $\begin{array}{l}\text { Y\&H scale: } 2-4 \\
\text { UPDRS score: } \\
29.9 \pm 11.9\end{array}$ & $\begin{array}{l}\text { Stimuli: } \\
\text { Whole-body random unsynchronised } \\
\text { vibration delivered to the feet ( } 5 \text { series } \\
\text { lasting } 1 \text { min each with 1-min rest in } \\
\text { between, frequency: mean of } 6 \mathrm{~Hz} \text { ) } \\
\text { Task: Standstill on a platform (ZEPTOR) } \\
\text { with knees slightly bent } \\
\text { Assessments: } \\
\text { UPDRS motor scores and subscales were } \\
\text { assessed at pre and post vibration }\end{array}$ & $\begin{array}{l}\text { Motor: } \\
\text { Improved overall UPDRS motor scores by } \\
16.8 \% \text { on treatment group after vibration } \\
\text { while the control group showed } \\
\text { non-significant changes } \\
\text { Greatest improvements in tremor }(25 \%) \text { and } \\
\text { rigidity }(24 \%) \text { scores, while gait }(15 \%), \\
\text { posture (15\%) and bradykinesia (12\%) } \\
\text { subscales showed a slight improvement }\end{array}$ & $\begin{array}{l}\text { Vibration therapy is experienced by the } \\
\text { whole-body and improves the motor } \\
\text { symptoms of PD (rigidity, tremors, gait, } \\
\text { posture, and bradykinesia) }\end{array}$ \\
\hline
\end{tabular}

Abbreviations: PD, Parkinson's Disease; NMT, Neurologic Music Therapy; RAS, Rhythmic Auditory Stimuli; ERS, Event-related Synchronisation; ERD, Event-related desynchronization; BG, Basal Ganglia; bpm, beat per minute; H\&Y scale, Hoehn and Yahr scale; UPDRS, Unified Parkinson's disease rating scale; BAASTA, Battery for the Assessment of Auditory Sensorimotor and Timing Abilities; Gold-MSI, Goldsmiths Musical Sophistication Index; FES, Falls Efficacy Scale;

FOGQ, Freezing of Gait Questionnaire; FGA, Functional Gait Assessment; BBS, Berg Balance Scale; 10MWT, 10 Meter Walk test; TUG, Timed Up and Go; GQI, gait quality index; DGI, Dynamic Gait Index. 

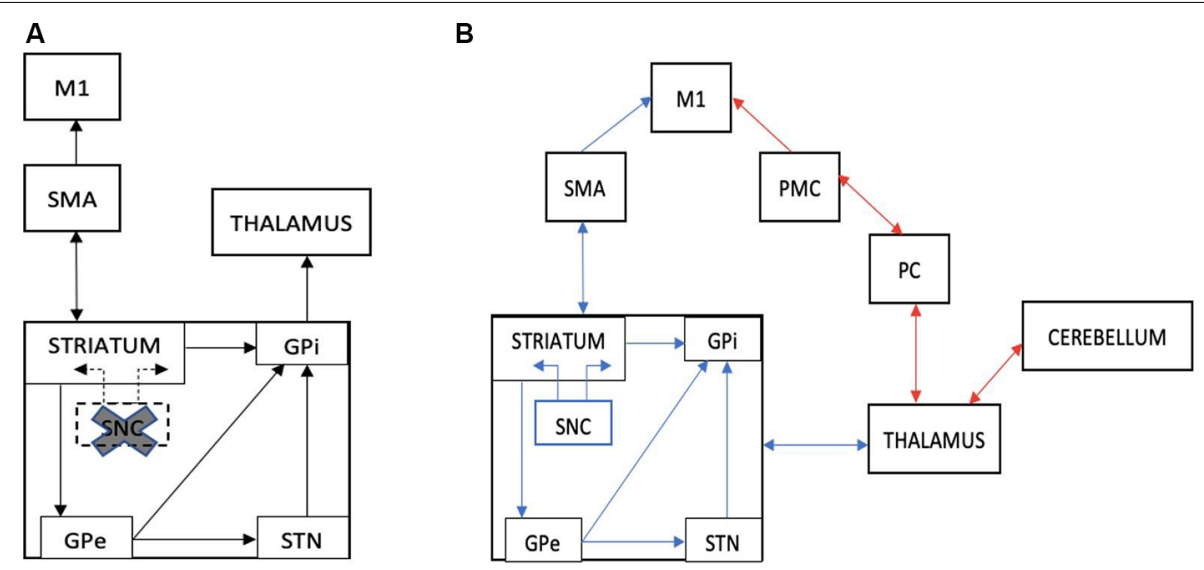

FIGURE 1 | (A) An illustration of the striato-thalamocortical motor loop that is impaired in Parkinson's disease (PD) due to dopamine depletion within the SNC of the basal ganglia (cross and dotted lines). (B) An illustration of The Compensation Hypothesis, which suggests recruitment of the cerebello-thalamocortical pathway that bypasses the BG (red lines). Alternatively, The Restoration Hypothesis suggests a facilitation effect on the striato-thalamocortical pathway, specifically facilitating dopaminergic function in the basal ganglia, (blue lines). M1, primary motor cortex; SMA, supplementary motor cortex; PMC, premotor cortex; PC, parietal cortex; SNC, substantia nigra pars compacta; GPe, external globus pallidus; GPi, internal globus pallidus; STN, subthalamic nucleus (adapted from Fujii and Wan, 2014).

changes associated with RAS. Future studies building on theory are thus encouraged to explore whether RAS facilitates movements by bypassing or/and facilitating the impaired BG network in PD.

\section{NEUROCHEMICAL EFFECTS OF RAS}

On top of neural network reorganization, studies have highlighted the neurochemical effects of RAS (Chanda and Levitin, 2013; Sihvonen et al., 2017; Cochen De Cock et al., 2018). Music listening not only activates emotional networks but also stimulates dopamine production in the striatal system (Salimpoor et al., 2011). Emotions and physical movements are closely intertwined (Molnar-Szakacs and Overy, 2006), hence there are suggestions that motor improvements following music intervention may be a result of emotional reactions mediating the dopaminergic activity of the BG motor loop (Salimpoor et al., 2011; Morris et al., 2019).

A recent PET study by Koshimori et al. (2019) explored RAS-induced dopamine responses in the BG of healthy participants while they performed finger-tapping tasks. They reported that RAS significantly decreased the binding potential relative to the non-displaceable compartment $\left(\mathrm{BP}_{\mathrm{ND}}\right)$ variability in the BG. Consequently, this led to a significant decrease in DA response in the left ventral striatum (VS), an area that plays a role in motivation and reward processing (Liljeholm and O'Doherty, 2012). The authors further explained that this decreased in DA response with RAS was associated with lesser motivational and attentional requirements while attending to the task, which could be beneficial in dopamine-deficient patients. This study, therefore, provided insights about the potential role of RAS to modulate dopamine responses in PD and warrant future studies with PD patients.

Morris et al. (2019) surveyed the music responses of people with and without PD. They observed that PD patients had a diminished connection between music and action, compared to controls who perceived music as a reward and felt motivated to sing or dance along. Motor responses during reward anticipation are mediated by the release of DA in the VS (Elliott et al., 2004), which is depleted in individuals with PD and may lack the motivation to act. If the results in Koshimori et al. (2019) study were taken into account, RAS may, therefore, be beneficial to individuals with PD as this intervention could lead to reduced DA response in the VS. Additionally, music mitigates motor impairments in PD by activating the emotional-limbic-network and inducing dopamine secretion within domains of reward and motivation (Chanda and Levitin, 2013), a process akin to taking dopamine medications. The reward centers remain connected to motor areas, whilst dopamine serves as reinforcement to motivate repeat behaviors individuals find pleasurable.

While the potential of RAS has been widely discussed, most studies do not specify the details of RAS, such as the type of acoustics employed and the intervention duration. Some studies presented metronome beats on their own (Dalla Bella et al., 2017; Rose et al., 2019), whereas others embedded beats within music selected by the patient (Thaut et al., 1996), or by therapists (McIntosh et al., 1997). Leow et al. (2014) proposed the use of familiar music/music with high beat salience during RAS therapy for better improvements in gait parameters, because less cognitive demand is required to entrain movement with familiar and strong beat structures. Furthermore, music enjoyment elicits an emotional response and serves as a good motivator during intervention programs. Acoustic-based intervention is also easier to incorporate into a patient's lifestyle as opposed to other physical therapies. A suggestion for future investigation would be to explore how different genres of music affect movement and emotional states of PD patients. They may also investigate optimal duration (number of sessions) alongside long-term effects of RAS therapy when patients are off medication, to observe if therapeutic effects are retained. 


\section{SOUND VIBRATION REDUCES TREMORS}

The bulk of acoustic-based intervention studies on PD report improvements in bradykinesia and speech functions using RAS. However, tremors are often the first symptoms in PD to be noticed. These can affect the hands, mouth, and limbs (Jankovic, 2008), impacting activities of daily living (Bhidayasiri, 2005). Very limited studies to date have explored how acoustic-based interventions help reduce or control tremors.

To our best knowledge, tremor reduction is evidenced in studies applying Vibroacoustic therapy (VAT; see Table 1). VAT delivers passive low-frequency sound vibrations $(20-100 \mathrm{~Hz})$ in contrast to RAS, the latter, an active form of acoustic therapy. In clinical settings, VAT supports the idea that patients should not only listen to music in isolation but sense vibrations as well (Warth et al., 2015). The VAT involves transducers embedded into chairs or mattresses, which send vibrations to and through the body. According to Punkanen and Ala-Ruona (2012), the best combination for VAT is a combination of music, sound waves and therapeutic interaction, which allows therapists to address a patient's mental and cognitive states, alongside motor function.

Skille and Wigram (1995) demonstrated that interventions involving music plus vibrations (40 and $55 \mathrm{~Hz}$ ) are most effective in enhancing/supporting movement while reducing muscle tension in physically disabled persons, in contrast to music as a solo acoustic therapy, indicating the importance of vibrations in neurorehabilitation. Studies that have implemented a combination of music and vibration in their intervention procedures include Chesky and Michel (1991), who reported vibroacoustic frequencies between $60-600 \mathrm{~Hz}$ to provide optimal pain relief; while Wigram (1996) reported decreased muscle tension, resulting in movement improvements in patients with cerebral palsy, post-intervention. Zheng et al. (2009) only applied low-frequency sound wave stimulation to frail, elderly participants, who later showed enhanced mobility. Nonetheless, many aspects of VAT are not clearly defined, and no agreement has been established regarding the necessity for music during VAT procedures. As such, the following section aims to discuss the individual roles of vibration and music in VAT, highlight studies that have applied vibration to reduce tremors in PD, and clarify possible mechanisms involved.

\section{THE RELAXATION HYPOTHESIS}

Studies that delivered vibrations to a single muscle (Jöbges et al., 2002) the entire body (Haas et al., 2006) or via physioacoustic chair (King et al., 2009) have demonstrated some level of efficacy in reducing tremors in individuals with PD. These studies further suggest that vibrations applied to manipulate local sensory feedback to the muscles, which decrease tremor frequency. One hypothesis for its effect is related to relaxation, which is based on the concepts of resonance, such that every part of our body has its natural frequency (Punkanen and Ala-Ruona, 2012). VAT frequencies presented via vibroacoustic chair may cause entrainment of our natural frequencies to resonate with external frequencies, resulting in increased blood circulation, enhanced metabolism, and decreased tension in muscles (Zheng et al., 2009; Punkanen and Ala-Ruona, 2012).

Tremors in individuals with PD are exacerbated when they are mentally and emotionally stressed (Schlesinger et al., 2009; Buhmann et al., 2018), and conversely reduced during mental relaxation; disappearing in sleep (Poliaková and Králová, 2015). The key to curtailing tremors may be to provide patients with a relaxed state of mind (Punkanen and AlaRuona, 2012). Zach et al. (2017) measured tremor intensity and variability while PD patients were performing a mental arithmetic task in ON and OFF L-Dopa medication. They found that cognitive stress reduced the effects of the medication on resting tremors, which highlights the importance of relaxation. Since the purpose of VAT is to achieve mental and muscular relaxation, adding a component of music has the potential to enhance relaxation, whilst encouraging patients to receive therapy, providing the music to be chosen correctly. Therefore, the type of music employed in acoustic therapy should be carefully determined because certain musical genres may at times be distracting, causing irritation or triggering unpleasant memories (Punkanen and Ala-Ruona, 2012). Future studies should aim to investigate the role of music in VAT by comparing therapeutic effects between vibration only and vibration plus music. Also, neural factors accompanying VAT have not been extensively explored. It is debatable whether tremor reduction after VAT is merely due to a state of relaxation, or the entrainment of thalamic oscillations.

Besides the relaxation hypothesis, Punkanen and Ala-Ruona (2012) have provided two other theories to explain the possible mechanisms underlying VAT. The first suggests low-frequency sound stimulates pain inhibitory mechanisms (i.e., Pacinian corpuscle), which mitigates pain impulse to the brain. In other words, VAT may be an effective pain reliever because inhibitory interneurons are activated in the process (Janzen et al., 2019). The second hypothesis is Jindrak postulate. Since the brain does not have a lymphatic drainage system, vibrations through it may assist the removal of waste molecules via diffusion through intercellular spaces (Skille and Wigram, 1995). However, these hypotheses do not explain how VAT is beneficial for relieving PD symptoms. A recent paper by Janzen et al. (2019) suggests vibroacoustic stimuli mimic brain stimulation (e.g., during transcranial electrical stimulation, wherein brain oscillations are induced), which in turn regulate thalamocortical dysrhythmias and enhance functional connectivity of the pain network in fibromyalgia patients. Based on this concept of neural entrainment, we may speculate that the delivery of rhythmic entrainment and sound vibration achieved with VAT can regulate abnormal neural oscillatory activity in PD (Teo et al., 2017). This hypothesis warrants further investigation to elaborate on the effects of vibroacoustic stimuli on neural oscillation and network connectivity.

\section{CONCLUSION}

In summary, there is growing evidence to support the beneficial effects of acoustic-based interventions in the form of music; rhythmic auditory cues; sound vibrations, or a combination 
of the three, in people with PD. Different PD symptoms can thus be treated with varying procedures such as RAS, which motivate the speed of movements, while sound vibration reduces involuntary shaking.

Herein, we propose directions for future research. If music serves as a relaxation tool to relieve symptoms, can individuals with $\mathrm{PD}$ habituate this form of relaxation to control their tremors through practice? As discussed, music plus vibration is far beneficial than either element alone; albeit systematic evidence to support this approach is necessary. Finally, the long-term effects of acoustic-mediated therapy in PD should be explored concerning its parameters (i.e., treatment duration; frequency; and type of music, where applicable)

\section{REFERENCES}

Altenmüller, E., Marco-Pallares, J., Münte, T. F., and Schneider, S. (2009). Neural reorganization underlies improvement in stroke-induced motor dysfunction by music-supported therapy. Ann. N Y Acad. Sci. 1169, 395-405. doi: 10.1111/j. 1749-6632.2009.04580.x

Ashoori, A., Eagleman, D. M., and Jankovic, J. (2015). Effects of auditory rhythm and music on gait disturbances in Parkinson's disease. Front. Neurol. 6:234. doi: 10.3389/fneur.2015.00234

Benoit, C. E., Dalla Bella, S., Farrugia, N., Obrig, H., Mainka, S., and Kotz, S. A. (2014). Musically cued gait-training improves both perceptual and motor timing in Parkinson's disease. Front. Hum. Neurosci. 8:494. doi: 10.3389/ fnhum.2014.00494

Bhidayasiri, R. (2005). Differential diagnosis of common tremor syndromes. Postgrad. Med. J. 81, 756-762. doi: 10.1136/pgmj.2005.032979

Buard, I., Dewispelaere, W. B., Thaut, M., and Kluger, B. M. (2019). Preliminary neurophysiological evidence of altered cortical activity and connectivity with neurologic music therapy in Parkinson's disease. Front. Neurosci. 13:105. doi: 10.3389/fnins.2019.00105

Buhmann, C., Jungnickel, D., and Lehmann, E. (2018). Stress management training (SMT) improves coping of tremor-boosting psychosocial stressors and depression in patients with Parkinson's disease: a controlled prospective study. Parkinsons Dis. 2018:4240178. doi: 10.1155/2018/4240178

Calabro, R. S., Naro, A., Filoni, S., Pullia, M., Billeri, L., Tomasello, P., et al. (2019). Walking to your right music: a randomized controlled trial on the novel use of treadmill plus music in Parkinson's disease J. Neuroeng. Rehabil. 16, 68. doi: 10.1186/s12984-019-0533-9

Chanda, M. L., and Levitin, D. J. (2013). The neurochemistry of music. Trends Cogn. Sci. 17, 179-193. doi: 10.1016/j.tics.2013.02.007

Chaudhuri, K. R., Healy, D. G., and Schapira, A. H. (2006). Non-motor symptoms of Parkinson's disease: diagnosis and management. Lancet Neurol. 5, 235-245. doi: 10.1016/S1474-4422(06)70373-8

Chesky, K. S., and Michel, D. E. (1991). The music vibration table $\left(\mathrm{MVT}^{\mathrm{mx}}\right)$ : developing a technology and conceptual model for pain relief. Music Ther. Perspect. 9, 32-38. doi: 10.1093/mtp/9.1.32

Cochen De Cock, V., Dotov, D. G., Ihalainen, P., Bégel, V., Galtier, F., Lebrun, C., et al. (2018). Rhythmic abilities and musical training in Parkinson's disease: do they help? NPJ Parkinsons Dis. 4:8. doi: 10.1038/s41531-018-0043-7

Dalla Bella, S., Benoit, C.-E., Farrugia, N., Keller, P. E., Obrig, H., Mainka, S., et al. (2017). Gait improvement via rhythmic stimulation in Parkinson's disease is linked to rhythmic skills. Sci. Rep. 7:42005. doi: 10.1038/srep42005

Elliott, R., Newman, J. L., Longe, O. A., and William Deakin, J. F. (2004). Instrumental responding for rewards is associated with enhanced neuronal response in subcortical reward systems. NeuroImage 21, 984-990. doi: 10.1016/j.neuroimage.2003.10.010

Fernandez del Olmo, M., Arias, P., Furio, M., Pozo, M., and Cudeiro, J. (2006). Evaluation of the effect of training using auditory stimulation on rhythmic movement in Parkinsonian patients-a combined motor and [18F]-FDG PET study. Parkinsonism Relat. Disord. 12, 155-164. doi: 10.1016/j.parkreldis.2005. 11.002 within each intervention. Systematic, longitudinal studies will greatly advance our understanding of music's applicability in neurorehabilitation.

\section{AUTHOR CONTRIBUTIONS}

JL: manuscript conceptualization, writing, and editing. LL and W-PT: manuscript writing and editing.

\section{FUNDING}

JL is supported by Nanyang Technological University (NTU) Research Scholarship.

Fujii, S., and Wan, C. Y. (2014). The role of rhythm in speech and language rehabilitation: the SEP hypothesis. Front. Hum. Neurosci. 8:777. doi: 10.3389/ fnhum.2014.00777

Ghai, S., Ghai, I., Schmitz, G., and Effenberg, A. O. (2018). Effect of rhythmic auditory cueing on parkinsonian gait: a systematic review and meta-analysis. Sci. Rep. 8:506. doi: 10.1038/s41598-017-16232-5

Gordon, C. L., Cobb, P. R., and Balasubramaniam, R. (2018). Recruitment of the motor system during music listening: an ALE meta-analysis of fMRI data. PLoS One 13:e0207213. doi: 10.1371/journal.pone.0207213

Grahn, J. A. (2009). The role of the basal ganglia in beat perception: neuroimaging and neuropsychological investigations. Ann. N Y Acad. Sci. 1169, 35-45. doi: 10.1111/j.1749-6632.2009.04553.x

Grahn, J. A., and Rowe, J. B. (2013). Finding and feeling the musical beat: striatal dissociations between detection and prediction of regularity. Cereb. Cortex 23, 913-921. doi: 10.1093/cercor/bhs083

Haas, C. T., Turbanski, S., Kessler, K., and Schmidtbleicher, D. (2006). The effects of random whole-body-vibration on motor symptoms in Parkinson's disease. NeuroRehabilitation 21, 29-36. doi: 10.3233/nre-2006-21105

Harrison, E. C., Horin, A. P., and Earhart, G. M. (2018). Internal cueing improves gait more than external cueing in healthy adults and people with Parkinson disease. Scienti. Rep. 8, 1-9.

Hunt, A. M. (2015). Boundaries and potentials of traditional and alternative neuroscience research methods in music therapy research. Front. Hum. Neurosci. 9:342. doi: 10.3389/fnhum.2015.00342

Jankovic, J. (2008). Parkinson's disease: clinical features and diagnosis. J. Neurol. Neurosurg. Psychiatry 79, 368-376. doi: 10.1136/jnnp.2007. 131045

Janzen, T. B., Paneduro, D., Picard, L., Gordon, A., and Bartel, L. R. (2019). A parallel randomized controlled trial examining the effects of rhythmic sensory stimulation on fibromyalgia symptoms. PLoS One 14:e0212021. doi: 10.1371/ journal.pone.0212021

Jöbges, E., Elek, J., Rollnik, J., Dengler, R., and Wolf, W. (2002). Vibratory proprioceptive stimulation affects Parkinsonian tremor. Parkinsonism Relat. Disord. 8, 171-176. doi: 10.1016/s1353-8020(01)00016-5

Jones, C. R., Malone, T. J., Dirnberger, G., Edwards, M., and Jahanshahi, M. (2008). Basal ganglia, dopamine and temporal processing: performance on three timing tasks on and off medication in Parkinson's disease. Brain Cogn. 68, 30-41. doi: 10.1016/j.bandc.2008.02.121

Kadivar, Z., Corcos, D. M., Foto, J., and Hondzinski, J. M. (2011). Effect of step training and rhythmic auditory stimulation on functional performance in Parkinson patients. Neuro. Neu. Repair 25, 626-635. doi: 10.1177/15459683 11401627

King, L. K., Almeida, Q. J., and Ahonen, H. (2009). Short-term effects of vibration therapy on motor impairments in Parkinson's disease. NeuroRehabilitation 25, 297-306. doi: 10.3233/NRE-2009-0528

Koshimori, Y., Strafella, A. P., Valli, M., Sharma, V., Cho, S.-S., Houle, S., et al. (2019). Motor synchronization to rhythmic auditory stimulation (RAS) attenuates dopaminergic responses in ventral striatum in young healthy adults: $\left[{ }^{11} \mathrm{C}\right]-(+)-P H N O$ PET study. Front. Neurosci. 13:106. doi: 10.3389/fnins. 2019.00106 
Leow, L. A., Parrott, T., and Grahn, J. A. (2014). Individual differences in beat perception affect gait responses to low- and high-groove music. Front. Hum. Neurosci. 8:811. doi: 10.3389/fnhum.2014.00811

Liljeholm, M., and O'Doherty, J. P. (2012). Contributions of the striatum to learning, motivation, and performance: an associative account. Trends Cogn. Sci. 16, 467-475. doi: 10.1016/j.tics.2012.07.007

Little, S., and Brown, P. (2012). What brain signals are suitable for feedback control of deep brain stimulation in Parkinson's disease? Ann. N Y Acad. Sci. 1265, 9-24. doi: 10.1111/j.1749-6632.2012.06650.x

Magee, W. L., and Davidson, J. W. (2002). The effect of music therapy on mood states in neurological patients: a pilot study. J. Music Ther. 39, 20-29. doi: 10.1093/jmt/39.1.20

McIntosh, G. C., Brown, S. H., Rice, R. R., and Thaut, M. H. (1997). Rhythmic auditory-motor facilitation of gait patterns in patients with Parkinson's disease. J. Neurol. Neurosurg. Psychiatry 62, 22-26. doi: 10.1136/jnnp.62.1.22

Molnar-Szakacs, I., and Overy, K. (2006). Music and mirror neurons: from motion to 'e'motion. Soc. Cogn. Affect. Neurosci. 1, 235-241. doi: 10.1093/scan/ nsl029

Morris, I. B., Vasudevan, E., Schedel, M., Weymouth, D., Loomis, J., Pinkhasov, T., et al. (2019). Music to one's ears: familiarity and music engagement in people with Parkinson's disease. Front. Neurosci. 13:661. doi: 10.3389/fnins.2019. 00661

Murgia, M., Pili, R., Corona, F., Sors, F., Agostini, T. A., Bernardis, P., et al. (2018). The Use of Footstep Sounds as Rhythmic Auditory Stimulation for Gait Rehabilitation in Parkinson's Disease: A Randomized Controlled Trial. Front. Neurol. 9:348. doi: 10.3389/fneur.2018.00348

Nilsson, U. (2008). The anxiety- and pain-reducing effects of music interventions: a systematic review. AORN J. 87, 780-807. doi: 10.1016/j.aorn.2007.09.013

Nombela, C., Hughes, L. E., Owen, A. M., and Grahn, J. A. (2013). Into the groove: can rhythm influence Parkinson's disease? Neurosci. Biobehav. Rev. 37 , 2564-2570. doi: 10.1016/j.neubiorev.2013.08.003

Poliaková, N., and Králová, E. (2015). 22. Potency of music and movement stimulation in the health care of patients with Parkinson's disease. Rev. Art. Educ. 9, 164-175.

Punkanen, M., and Ala-Ruona, E. (2012). Contemporary vibroacoustic therapy: perspectives on clinical practice, research, and training. Music Med. 4, 128-135. doi: $10.1177 / 1943862112445324$

Raglio, A. (2015). Music therapy interventions in Parkinson's disease: the state-ofthe-art. Front. Neurol. 6:185. doi: 10.3389/fneur.2015.00185

Reeve, A., Simcox, E., and Turnbull, D. (2014). Ageing and Parkinson's disease: why is advancing age the biggest risk factor? Ageing Res. Rev. 14, 19-30. doi: 10.1016/j.arr.2014.01.004

Rizek, P., Kumar, N., and Jog, M. S. (2016). An update on the diagnosis and treatment of Parkinson disease. CMAJ 188, 1157-1165. doi: 10.1503/cmaj. 151179

Rochester, L., Burn, D. J., Woods, G., Godwin, J., and Nieuwboer, A. (2009). Does auditory rhythmical cueing improve gait in people with Parkinson's disease and cognitive impairment? A feasibility study. Mov. Disord. 24, 839-845. doi: $10.1002 / \mathrm{mds} .22400$

Rohenkohl, G., Cravo, A. M., Wyart, V., and Nobre, A. C. (2012). Temporal expectation improves the quality of sensory information. J. Neurosci. 32, 8424-8428. doi: 10.1523/JNEUROSCI.0804-12.2012

Rose, D., Delevoye-Turrell, Y., Ott, L., Annett, L. E., and Lovatt, P. J. (2019). Music and metronomes differentially impact motor timing in people with and without Parkinson's disease: effects of slow, medium, and fast tempi on entrainment and synchronization performances in finger tapping, toe tapping, and stepping on the spot tasks. Parkinsons Dis. 2019:6530838. doi: 10.1155/2019/6530838

Salimpoor, V. N., Benovoy, M., Larcher, K., Dagher, A., and Zatorre, R. J. (2011). Anatomically distinct dopamine release during anticipation and experience of peak emotion to music. Nat. Neurosci. 14, 257-262. doi: 10.1038/nn.2726

Schlesinger, I., Benyakov, O., Erikh, I., Suraiya, S., and Schiller, Y. (2009). Parkinson's disease tremor is diminished with relaxation guided imagery. Mov. Disord. 24, 2059-2062. doi: 10.1002/mds.22671

Schwartze, M., Keller, P. E., Patel, A. D., and Kotz, S. A. (2011). The impact of basal ganglia lesions on sensorimotor synchronization, spontaneous motor tempo and the detection of tempo changes. Behav. Brain Res. 216, 685-691. doi: 10.1016/j.bbr.2010.09.015
Sen, S., Kawaguchi, A., Truong, Y., Lewis, M. M., and Huang, X. (2010). Dynamic changes in cerebello-thalamo-cortical motor circuitry during progression of Parkinson's disease. Neuroscience 166, 712-719. doi: 10.1016/j.neuroscience. 2009.12.036

Sharott, A., Gulberti, A., Zittel, S., Tudor Jones, A. A., Fickel, U., Munchau, A., et al. (2014). Activity parameters of subthalamic nucleus neurons selectively predict motor symptom severity in Parkinson's disease. J. Neurosci. 34, 6273-6285. doi: 10.1523/JNEUROSCI.1803-13.2014

Sihvonen, A. J., Särkämö, T., Leo, V., Tervaniemi, M., Altenmüller, E., and Soinila, S. (2017). Music-based interventions in neurological rehabilitation. Lancet Neurol. 16, 648-660. doi: 10.1016/S1474-4422(17)30168-0

Skille, O., and Wigram, T. (1995). "The effect of music, vocalisation and vibration on brain and muscle tissue: studies in vibroacoustic therapy," in The Art and Science of Music Therapy: A Handbook, eds T. Wigram, B. Saperston and R. West (London: Harwood Academic) pp. 23-57.

Sveinbjornsdottir, S. (2016). The clinical symptoms of Parkinson's disease. J. Neurochem. 139, 318-324. doi: 10.1111/jnc.13691

Teo, W. P., Hendy, A. M., Goodwill, A. M., and Loftus, A. M. (2017). Transcranial alternating current stimulation: a potential modulator for pathological oscillations in Parkinson's disease? Front. Neurol. 8:185. doi: 10.3389/fneur. 2017.00185

Thaut, T. H. (2005). The future of music in therapy and medicine. Ann. N Y Acad. Sci. 1060, 303-308. doi: 10.1196/annals.1360.023

Thaut, M. H., McIntosh, G. C., Rice, R. R., Miller, R. A., Rathbun, J., and Brault, J. M. (1996). Rhythmic auditory stimulation in gait training for Parkinson's disease patients. Mov. Disord. 11, 193-200. doi: 10.1002/mds. 870110213

Thaut, M. H., Stephan, K. M., Wunderlich, G., Schicks, W., Tellmann, L., Herzog, H., et al. (2009). Distinct cortico-cerebellar activations in rhythmic auditory motor synchronization. Cortex 45, 44-53. doi: 10.1016/j.cortex.2007. 09.009

Todd, N. P., and Lee, C. S. (2015). The sensory-motor theory of rhythm and beat induction 20 years on: a new synthesis and future perspectives. Front. Hum. Neurosci. 9:444. doi: 10.3389/fnhum.2015.00444

Vorovenci, R. J., Biundo, R., and Antonini, A. (2016). Therapy-resistant symptoms in Parkinson's disease. J. Neural Transm. 123, 19-30. doi: 10.1007/s00702-0151463-8

Warth, M., Kessler, J., Kotz, S., Hillecke, T. K., and Bardenheuer, H. J. (2015). Effects of vibroacoustic stimulation in music therapy for palliative care patients: a feasibility study. BMC Complement. Altern. Med. 15:436. doi: 10.1186/s12906015-0933-8

Wigram, A. L. (1996). The Effects of Vibroacoustic Therapy on Clinical and Non-Clinical Populations. London: University of London.

Woerd, E. S., Oostenveld, R., de Lange, F. P., and Praamstra, P. (2014). A shift from prospective to reactive modulation of $\beta$-band oscillations in Parkinson's disease. NeuroImage 100, 507-519. doi: 10.1016/j.neuroimage.2014.06.039

Zach, H., Dirkx, M. F., Pasman, J. W., Bloem, B. R., and Helmich, R. C. (2017). Cognitive stress reduces the effect of levodopa on Parkinson's resting tremor. CNS Neurosci. Ther. 23, 209-215. doi: 10.1111/cns.12670

Zatorre, R. J., Chen, J. L., and Penhune, V. B. (2007). When the brain plays music: auditory-motor interactions in music perception and production. Nat. Rev. Neurosci. 8, 547-558. doi: 10.1038/nrn2152

Zheng, A., Sakari, R., Cheng, S., Hietikko, A., Moilanen, P., Timonen, J., et al. (2009). Effects of a low-frequency sound wave therapy programme on functional capacity, blood circulation and bone metabolism in frail old men and women. Clin. Rehabil. 23, 897-908. doi: 10.1177/0269215509337273

Conflict of Interest: The authors declare that the research was conducted in the absence of any commercial or financial relationships that could be construed as a potential conflict of interest.

Copyright (c) 2020 Leuk, Low and Teo. This is an open-access article distributed under the terms of the Creative Commons Attribution License (CC BY). The use, distribution or reproduction in other forums is permitted, provided the original author(s) and the copyright owner(s) are credited and that the original publication in this journal is cited, in accordance with accepted academic practice. No use, distribution or reproduction is permitted which does not comply with these terms. 